\title{
Neonatal Sepsis as a Major Cause of Morbidity in a Tertiary Center in Kathmandu
}

\author{
Badri Thapa, ${ }^{1}$ Anurag Thapa, ${ }^{1}$ Dhan Raj Aryal, ${ }^{2}$ Kusum Thapa, ${ }^{2}$ Asha Pun, ${ }^{3}$ Sudhir Khanal, ${ }^{3}$ Kishori Mahat ${ }^{4}$ \\ 'Genesis Laboratory and Research, Kathmandu, ${ }^{2}$ Paropakar Maternity and Women's Hospital, Kathmandu, Nepal, \\ ${ }^{3}$ UNICEF, Country Office for Nepal, Kathmandu, ${ }^{4}$ SOPHYN, Kathmandu, Nepal.
}

Introduction: Neonatal sepsis causes high morbidity and mortality of newborns. The study aims to study the predictors and clinical, haematological and bacteriological factors of neonatal sepsis.

Methods: A descriptive cross sectional study was conducted in a Neonatal Intensive Care Unit of Paropakar Maternity and Women's Hospital in Kathmandu between October and December 2011. Demographic, obstetrics, clinical and microbiological data were studied for 300 neonates.

Results: The NICU prevalence rate of sepsis was $37.12 \%$. Early onset neonatal sepsis was common (91.39\%) ( $\mathrm{P}=0.001)$. Cesarean section (OR 1.95, 95\% CI 1.15-3.31), apgar score $<4$ at $1 \mathrm{~min}(\mathrm{P}=0.001)$ and $<7$ at $5 \mathrm{~min}$ of birth $(\mathrm{P}=0.001)$ predicted sepsis. Neonates with sepsis were more likely to present with hypothermia (OR 1.180, 95\% CI 0.080-17.214), pustules (OR 2.188, 95\% CI 0.110-43.465), dehydration (OR 3.040, 95\% CI 0.170-54.361), diminished movement (OR 3.082, 95\% CI 0.433-21.950) and bulging fontanels (OR 16.464, 95\% CI 0.007-41495.430). Coagulase negative Staphylococcus spp. (CoNS) $(21,41.17 \%)$ was most common pathogen of neonatal sepsis. Variable antibiotic resistance patterns of isolates with emergence of meropenem resistance in Pseudomonas spp. and methicillin resistance in CoNS and S. aurues were noted. Mortality due to sepsis was highest $(15,8.06 \%)$ among total mortalities $(21,11.29 \%)$.

Conclusions: Delivery via cesarian section, apgar score $<4$ at $1 \mathrm{~min}$, and $<7$ at $5 \mathrm{~min}$ predicted sepsis. Morbidity and mortality of neonatal sepsis was common in this setting and early maternal and neonatal interventions are required to address this issue.

Keywords: morbidity; mortality; neonatal sepsis; predictors.

\section{INTRODUCTION}

Sepsis is the commonest cause of neonatal mortality, which may either have non-specific features or focal signs of infection. ${ }^{1-3}$ Various fetal and maternal risk factors have been associated with an increased risk of early onset sepsis. ${ }^{4}$

The most common pathogens causing neonatal sepsis include Escherichia coli, Klebsiella pnemoniae, Citrobacter spp., Proteus spp., Staphylococcus aureus and coagulase negative Staphylococcus spp. (CoNS). 5,6
Likewise, K. pneumoniae, S. aureus, Pseudomonas spp, and E. coli are the primary pathogens in Asia, India, Africa, Middle East and West Indies are primarily due to. Group B Streptococcus is infrequent. ${ }^{6}$

Ministry of Health and Population, Government of Nepal has started "AAMA" program (free maternity

Correspondence: Dr. Badri Thapa, Genesis Laboratory and Research, Kathmandu, Nepal. Email:badri_bishal@yahoo.com, Phone: $+977-9801220108$. 
service) to motivate institutional delivery, which has provided skilled maternal care at birth. However, the neonatal mortality rate is still high. One of the most important causes of mortality is neonatal sepsis. ${ }^{7}$ This study evaluated newborns for neonatal sepsis in Paropakar Maternity and Women's Hospital (PMWH) in Kathmandu, Nepal.

\section{METHODS}

This was a descriptive cross sectional study conducted between October and December 2011 in Neonatal Intensive Care Unit (NICU) of PMWH, Kathmandu, Nepal. This is a 500 bedded tertiary care hospital offering gynecological and obstetrics services. All neonates born in PMWH and admitted in NICU who were being evaluated for neonatal sepsis were enrolled. Case definition for confirmed sepsis, probable sepsis, clinical sepsis, early onset neonatal sepsis (EoNS), late onset neonatal sepsis (LoNS), symptoms and signs for neonatal sepsis were used as described previously. ${ }^{8-10}$ Neonates admitted in the NICU in whom the signs and symptoms of sepsis were absent, blood culture was negative, hematological score was $<3$ and antibiotics were not used were used as controls. Death due to sepsis was defined as the death of neonates meeting the criteria of neonatal sepsis, clinical sepsis and probable sepsis. Controls were neonates in whom sepsis was not documented clinically and in whom lab evidences of sepsis was not present.

Neonatal whole blood was collected from a peripheral vein with all aseptic precautions. Six hundred microliter of blood was inoculated in the pediatric culture bottle containing $6 \mathrm{ml}$ of Brain Heart Infusion broth (HiMedia Pvt. Ltd.). The cultures were incubated, subcultured and the pathogens were identified based on the established procedures. ${ }^{11}$ AST was performed using Kirby-Bauer disk diffusion test following the manufacture's guidelines (HiMedia Pvt. Ltd., India). Following antibiotic discs ( $\mu \mathrm{g} / \mathrm{disc})$ were used. Amilkacin (30), Cloxacillin (30), Cefoxitin (30), Ceftriaxone (30), Meropenem (10) and Vancomycin (30) were used for Gram-positive organisms. Amikacin (30), Gentamicin (30), Ciprofloxacin (5), Ceftraixone (30), Ceftazidime (30) and Meropenem (10) were used for Gram-positive and Gram-negative bacilli. ATCC strains E. coli 25922 and S. aureus strain ATCC 25923 were used as a quality control strains in antibiotic susceptibility tests.

Complete blood counts, haemoglobin, microESR, $\mathrm{C}$-reactive protien were determined in all neonates at the time of evaluation for sepsis on venipunctured blood sample. Neutrophil indices were calculated as previously described by Manroe et al. ${ }^{12}$ All hematological parameters were an average reading taken by the two independent laboratory personnel (laboratory technologist and a consultant pathologist) working at the routine hematology laboratory. Neonates were categorized as neonatal sepsis based on the published hematological scoring system with slight modification. ${ }^{13}$ A score of 1 for each of eight findings: abnormal total leukocyte count ( $>12000 / \mathrm{cmm}$ or $<4000 / \mathrm{cmm}$ ) and abnormal total neutrophil (ANC) count based on age related values $(<7500$ and $>14500 \mathrm{cmm})$, elevated immature neutrophil (IM) count (>7\%), elevated immature to total neutrophil ratio (IM/TN) ( $\geq 0.20)$, elevated immature to mature neutrophil ratio (IM:MN) $(\geq 0.30)$, platelet count $(\leq 150,000 / \mathrm{cmm})$, and positive C-reactive protein (CRP) ( $\geq 12 \mathrm{mg} / \mathrm{l})$. Hematological score $\geq 3$ was considered positive for neonatal sepsis.

\section{Data collection and statistics}

Clinical, demographic, obstetric and laboratory data were collected and entered into statistical package for social science version 16 (SPSS V16). Logistic regression analysis was performed to find out the predictors of neonatal sepsis. Odds ratio (OR) and 95\% Confidence interval $(\mathrm{Cl})$ was obtained. The difference in means between groups was compared by Student's $t$ test. The $P$ value of $<0.05$ was considered statistically significant. The consent was taken from the mothers. The study was approved by the institutional review board of PMWH.

\section{RESULTS}

Total of 4394 deliveries took place at PMWH Hospital during the study period. Of these newborns 501 $(11.4 \%)$ neonates were admitted to NICU. Out of them, $300(59.88 \%)$ neonates were evaluated for sepsis. The prevalence of neonatal sepsis in NICU was $37.12 \%$ $(186 / 501)$. Among sepsis, the prevalence rate of EoNS $(170,91.39 \%)$ was higher than LoNS $(16,8.60 \%)$ $(\mathrm{P}=0.000)$. Among the studied neonates, the most common morbidity was neonatal sepsis $(186,62.00 \%)$ followed by the neonates born to CRP positive mothers (64, 21.33\%) (Figure 1).

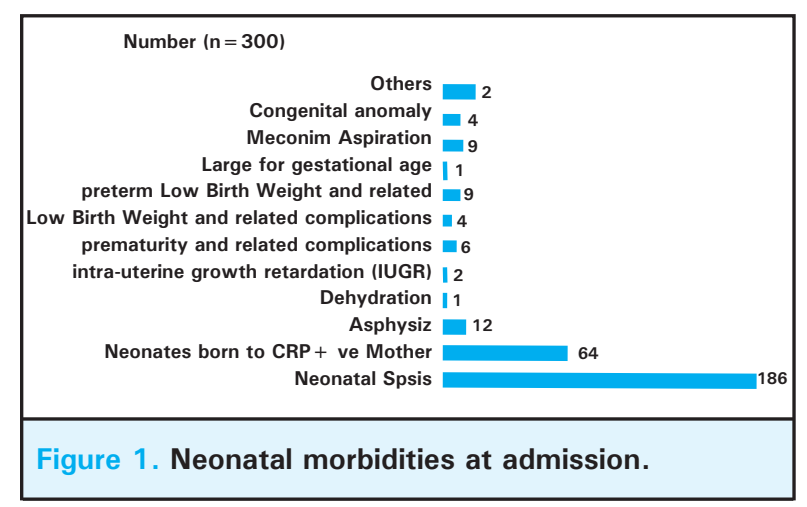


There was no significant difference in age between two groups of mothers $(P=0.32)$ (Table 1). Delivery via cesarean section (OR 1.95, 95\% Cl 1.15-3.31), apgar score less than 4 at 1 min of birth $(P=0.00)$ and apgar score less than 7 at 5 min of birth $(P=0.00)$ predicted sepsis. Mothers and neonatal variables like, gestational age $<37$ weeks (OR 1.57, 95\% Cl 0.93-2.67), maternal fever one or two weeks before delivery (OR $1.02,95 \% \mathrm{Cl} 0.48-2.34)$, multiparity (OR 1.33, 95\% $\mathrm{Cl} 0.82-2.16$ ), PROM more than 24 hours (OR 1.55, $95 \% \mathrm{Cl} 0.29-8.11$ ) and female baby (OR 1.03, $95 \% \mathrm{Cl}$ 0.64- 1.69) were more likely to develop neonatal sepsis although none of these were statistically significant.

Table 1. Neonatal and maternal characteristics in relation to neonatal sepsis.

\begin{tabular}{|c|c|c|c|}
\hline Characteristics & $\begin{array}{l}\text { Sepsis } \\
(\mathrm{N}=186)\end{array}$ & No sepsis $(N=114)$ & $\begin{array}{c}\text { OR }(95 \% \mathrm{Cl}) * \text { difference in } \\
\text { mean } \dagger, \mathrm{P} \text { value }\end{array}$ \\
\hline Maternal age, (mean \pm SD) & $24.82 \pm 5.16$ & $24.23 \pm 4.81$ & $0.59, P=0.32$ \\
\hline \multicolumn{4}{|l|}{ Parity } \\
\hline Primi, n (\%) & $110(59.13)$ & $75(65.78)$ & $1.00 \ddagger$ \\
\hline Multi, n (\%) & $76(40.86)$ & $39(34.21)$ & $1.33(0.82-2.16)$ \\
\hline Maternal fever, n (\%) & $16(8.60)$ & $10(8.77)$ & $1.02(0.48-2.34)$ \\
\hline PV examination $(>5), \mathrm{n}(\%)$ & $114(61.29)$ & $64(44.44)$ & $1.24(0.77-1.98)$ \\
\hline PROM (> 24 hrs), n (\%) & $5(2.68)$ & $2(1.75)$ & $1.55(0.29-8.11)$ \\
\hline Foul smelling liquor, n (\%) & $14(7.53)$ & $10(8.77)$ & $0.85(0.38-1.97)$ \\
\hline \multicolumn{4}{|l|}{ Mode of delivery } \\
\hline Vaginal, n (\%) & $118(63.44)$ & 88 (77.19) & $1.00 \ddagger$ \\
\hline Cesarean section, n (\%) & $68(36.55)$ & $26(22.80)$ & $1.95(1.15-3.31)$ \\
\hline \multicolumn{4}{|l|}{ Sex of baby } \\
\hline Male, n (\%) & $108(58.06)$ & $67(58.77)$ & $1.00 \ddagger$ \\
\hline Female, n (\%) & $78(41.93)$ & $47(41.22)$ & $1.03(0.64-1.69)$ \\
\hline Apgar score at $1 \mathrm{~min}$, mean $\pm \mathrm{SD}$ & $4.67 \pm 1.91$ & $5.54 \pm 1.52$ & $0.87, P=0.000$ \\
\hline Apgar score at $5 \mathrm{~min}$, mean $\pm \mathrm{SD}$ & $6.41 \pm 1.95$ & $7.25 \pm 1.43$ & $0.84, P=0.000$ \\
\hline Gestational age ( $<37$ weeks), n (\%) & $61(32.79)$ & $21(18.42)$ & $1.57(0.93-2.67)$ \\
\hline Body weight $(<2500 \mathrm{gms})$, n (\%) & $79(42.47)$ & $107(93.85)$ & $0.85(0.53-1.37)$ \\
\hline IUGR, n (\%) & $4(2.15)$ & $2(1.75)$ & $0.83(0.15-4.51)$ \\
\hline
\end{tabular}

* Binary logistic regression analysis; absence of maternal fever, foul smelling liquor and IUGR, PROM $<24$ hours, gestational age $>37$ weeks, body weight $>2500$ grams were used as reference category in binary logistic regression. †Difference between means, Student's t test.

‡Reference category in binary logistic regression analysis.

The commonest clinical presentation of neonatal sepsis was tachypnea (39.25\%), grunting $(38.71 \%)$, poor feeding $(24.73 \%)$, poor cry $(23.66 \%)$, cyanosis $(22.04 \%)$ and vomiting $(18.81 \%)$ (Table 2$)$.

Grunting (41.18\%), tachypnoea $(40.59 \%)$, poor feeding $(25.88 \%)$, poor cry $(24.71 \%)$ and cyanosis $(23.55 \%)$ were common presentations of early neonatal sepsis while fever $\geq 37.5$ (62.50), irritability $(37.50 \%)$ and clinical severe jaundice $(37.50 \%)$ were common clinical presentation for LoNS (data not shown). Neonates presenting with hypothermia (OR 1.180, 95\% $\mathrm{Cl} 0.080-17.214$ ), pustules (>10) (OR 2.188, 95\% $\mathrm{Cl} 0.110-43.465)$, dehydration (OR 3.040, $95 \% \mathrm{Cl}$ 0.170-54.361), diminished movement (OR 3.082, $95 \%$ $\mathrm{Cl}$ 0.433-21.950) and bulging fontanels (OR 16.464,
$95 \% \mathrm{Cl}$ 0.007-41495.430) were more likely to develop neonatal sepsis but were not statistically significant $(P>0.05)$.

Fifty one cultures were positive for micro-organisms $(17.00 \%)$. The ratio of Gram positive to negative was 37:14. Among Gram positives, CoNS was most commonly encountered (21, $(41.17 \%)$ (Table 3). Nine isolates of CoNS were methicillin resistant $(42.85 \%)$. Staphylococcus aureus $(15,29.41 \%)$ was also common of which Methicillin resistant S. aureus (MRSA) were $26.66 \%(n=4)$. Gram negative bacteria like, Pseudomonas spp. (5, 9.80\%), Acinetobacter spp. (5, $9.80 \%)$, and $\mathrm{K}$. pneumoniae $(4,7.84 \%)$ were isolated. Majority of the bacterial isolates $(46,90.20 \%)$ were isolated from EoNS (data not shown). All Gram negative 
Thapa et al. Neonatal Sepsis as a Major Cause of Morbidity in a Tertiary Center in Kathmandu

\begin{tabular}{|c|c|c|c|}
\hline Variables* & $\begin{array}{c}\text { Sepsis }(n=186) \\
n(\%)\end{array}$ & $\begin{array}{c}\text { No sepsis } \\
(N=114) \\
n(\%)\end{array}$ & OR $(95 \% \mathrm{Cl}) \dagger$ \\
\hline \multicolumn{4}{|l|}{ Systemic } \\
\hline Fever & $27(14.51)$ & $2(1.75)$ & $0.223(0.042-1.184)$ \\
\hline Hypothermia & $8(4.30)$ & $1(0.88)$ & $1.180(0.080-17.214)$ \\
\hline Jaundice & $39(20.97)$ & $9(7.89)$ & $0.761(0.287-2.023)$ \\
\hline Cyanosis & $41(22.04)$ & $5(4.39)$ & $0.403(0.134-1.217)$ \\
\hline Pustules (>10) & $1(0.53)$ & $1(0.88)$ & $2.188(0.110-43.465)$ \\
\hline Dehydration & $4(2.15)$ & $1(0.88)$ & $3.040(0.170-54.361)$ \\
\hline \multicolumn{4}{|l|}{ Gastrointestinal } \\
\hline Vomiting & $35(18.81)$ & $3(2.63)$ & $0.218(0.049-0.971)$ \\
\hline Abdominal distension & $8(4.30)$ & $1(0.88)$ & $0.513(0.044-5.965)$ \\
\hline \multicolumn{4}{|l|}{ Neurological } \\
\hline Diminished movement & $24(12.90)$ & $4(3.51)$ & $3.082(0.433-21.950)$ \\
\hline Poor cry & $44(23.66)$ & $6(5.26)$ & $0.622(0.190-2.034)$ \\
\hline Poor feeding & $46(24.73)$ & $6(5.26)$ & $0.436(0.137-1.392)$ \\
\hline Irritability & $35(18.82)$ & $1(0.88)$ & $0.135(0.014-1.278)$ \\
\hline Convulsion & $18(9.68)$ & $1(0.88)$ & $0.448(0.044-4.515)$ \\
\hline Lethargy & $30(16.13)$ & $3(2.63)$ & $0.979(0.150-6.406)$ \\
\hline Apnoea & $21(11.29)$ & $2(1.75)$ & $0.387(0.046-3.270)$ \\
\hline Bulging frontanels & $3(1.61)$ & $1(0.88)$ & $16.464(0.007-414.430)$ \\
\hline \multicolumn{4}{|l|}{ Respiratory } \\
\hline Tachynopoea & $72(38.71)$ & $12(10.53)$ & $0.338(0.145-0.790)$ \\
\hline Grunting & $72(38.71)$ & $21(18.52)$ & $0.902(0.422-1.933)$ \\
\hline Lower chest wall indrawing & $41(22.04)$ & $3(2.63)$ & $0.410(0.097-1.733)$ \\
\hline
\end{tabular}

\begin{tabular}{|c|c|c|c|c|c|c|c|c|c|c|c|c|c|c|c|c|}
\hline \multirow{2}{*}{ 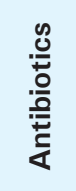 } & \multicolumn{2}{|c|}{$\begin{array}{l}\text { CoNS } \\
(n=21)\end{array}$} & \multicolumn{2}{|c|}{$\begin{array}{c}\text { S. } \\
\text { aureus } \\
(n=15)\end{array}$} & \multicolumn{2}{|c|}{ Total } & \multicolumn{2}{|c|}{$\begin{array}{c}\text { K. } \\
\text { pneumoniae } \\
(n=4)\end{array}$} & \multicolumn{2}{|c|}{$\begin{array}{l}\text { Acinetobacter } \\
\text { spp. }(n=5)\end{array}$} & \multicolumn{2}{|c|}{$\begin{array}{l}\text { Pseudomonas } \\
\text { spp. }(n=5)\end{array}$} & \multicolumn{2}{|c|}{$\begin{array}{c}\mathrm{L} . \\
\text { monocytogenes } \\
(\mathrm{n}=1)\end{array}$} & \multicolumn{2}{|c|}{ Total } \\
\hline & $\mathrm{R}$ & $S$ & $\mathrm{R}$ & $\mathrm{S}$ & $\mathrm{R}$ & $S$ & $\mathrm{R}$ & $S$ & $\mathrm{R}$ & $S$ & $\mathrm{R}$ & $S$ & $\mathrm{R}$ & $S$ & $\mathrm{R}$ & S \\
\hline Ak & 11 & 10 & 4 & 11 & 15 & 21 & 1 & 3 & 1 & 4 & 0 & 5 & 0 & 1 & 2 & 13 \\
\hline Gen & - & - & - & - & & & 1 & 3 & 2 & 3 & 0 & 5 & 0 & 1 & 3 & 12 \\
\hline Cip & - & - & - & - & & & 1 & 3 & 0 & 5 & 1 & 4 & 0 & 1 & 2 & 13 \\
\hline Cox & 11 & 10 & 6 & 9 & 17 & 19 & - & - & - & - & - & - & - & - & & \\
\hline $\mathbf{C i}$ & 13 & 8 & 5 & 10 & 18 & 18 & 2 & 2 & 1 & 4 & 0 & 5 & 0 & 1 & 3 & 12 \\
\hline Caz & - & - & - & - & & & 2 & 2 & 2 & 3 & 0 & 5 & 1 & 0 & 5 & 10 \\
\hline Mrp & 11 & 10 & 5 & 10 & 16 & 20 & 1 & 3 & 0 & 5 & 3 & 2 & 0 & 1 & 4 & 11 \\
\hline Va & 1 & 20 & 0 & 15 & 1 & 35 & - & - & - & - & - & - & - & - & & \\
\hline
\end{tabular}

Ak, amikacin; Gen,gentamicin; Cip, ciprofloxacin; Cox, coxacillin; Ci, ceftriaxone; Caz, ceftazidime;Mrp, meropenem; Va, vancomycin; CoNS, Coagulase negative Staphylococcus spp.; R, Resistant; S, Sensitive. "“", not tested. Resistant and sensitive strains are expressed in numbers. 9 and 4 isolates of CoNS and S. aureus were Methicillin resistant, respectively. 
Thapa et al. Neonatal Sepsis as a major cause of morbidity in a Tertiary Center in Kathmandu

bacteria $(14,27.45 \%)$ were isolated in late neonatal sepsis (data not shown). Listeria monocytogenes was uncommon $(1,1.96 \%)$.

Gram positives were mostly resistant to 5 antibiotics tested except vancomycin. CoNS were found resistant to amikacin $(n=11)$, coxacillin $(n=11)$, ceftriaxone $(n=13)$ and meropenem $(n=11)$. Similarly, S. aureus was resistant to Amikaicn $(n=4)$, coxacillin $(n=6)$, ceftriaxone $(n=5)$ and meropenem $(n=5)$. Few Gram negative isolates were resistant to amikacin (2, $13.33 \%)$, gentamicin $(n=3)$, ciprofloxacin $(n=2)$, ceftriaxone $(n=3)$, ceftazidime $(n=5)$ and meropenem $(n=4)$. Isolates of Pseudomoas spp. were more resistant to meropenem $(n=3)$.

Among the neonates studied, $262(87.33 \%)$ neonates were cured, $8(2.66 \%)$ were referred, $9(3.00 \%)$ left against medical advice and 21 died (OR $0.357,95 \% \mathrm{Cl}$ 0.036-3.560) (Table 4).

\begin{tabular}{|c|c|c|c|}
\hline Outcomes & $\begin{array}{l}\text { Sepsis } \\
(n=186) \\
n(\%)\end{array}$ & $\begin{array}{l}\text { No sepsis } \\
(n=114) \\
n(\%)\end{array}$ & $\begin{array}{l}\text { OR }(95 \% \\
\mathrm{CI})\end{array}$ \\
\hline Cured & $\begin{array}{l}158 \\
(84.94)\end{array}$ & $\begin{array}{l}104 \\
(91.22)\end{array}$ & $1.000 *$ \\
\hline Referred & $7(3.76)$ & $1(0.88)$ & $\begin{array}{l}1.646 \\
(0.618- \\
4.378)\end{array}$ \\
\hline $\begin{array}{l}\text { Left } \\
\text { against } \\
\text { medical } \\
\text { advice }\end{array}$ & $6(3.22)$ & $3(2.63)$ & $\begin{array}{l}0.357 \\
(0.036- \\
3.560)\end{array}$ \\
\hline Died & $15(8.06)$ & $6(5.26)$ & $\begin{array}{l}1.250 \\
(0.233- \\
6.696)\end{array}$ \\
\hline
\end{tabular}

OR $(95 \% \mathrm{Cl})$ based on multiple logistic regression analysis, $1.000 *$ reference category

Out of 186 neonates with sepsis, 158 (84.94\%) were cured, seven $(3.76 \%)$ were referred and $15(8.06 \%)$ died. Out of fifteen neonates who died of sepsis, 13 $(88.66 \%)$ neonates died of EoNS and 2 (13.33\%) neonates died of late onset sepsis (data not shown). Similarly, one neonate died of aspiration, two of asphyxia, one of preterm and another one of low birth weight and congenital anomaly. Seven (3.76\%) neonates who had sepsis were more likely to be referred (OR 1.646, 95\% Cl 0.618-4.378) and 15 (8.06\%) neonates who had sepsis were more likely to die (OR $1.250,95 \% \mathrm{Cl}$ 0.233-6.696). Neonatal mortality rate in NICU was $4.19 \%$ and neonatal mortality rate due to sepsis was $2.99 \%$

\section{DISCUSSION}

Most of the 4 million neonatal deaths every year are in low-income and middle-income countries. ${ }^{14}$ Infections account for an estimated 1.44 million (36\%) deaths, and about half of deaths in regions with high neonatal mortality rates. ${ }^{15}$ Among infections, neonatal sepsis is one of the leading causes of neonatal morbidity and mortality in developing countries as well as in Nepal. ${ }^{16,17}$ In this study, the prevalence rate of neonatal sepsis in NICU was $37.12 \%$. The prevalence is higher than the prevalence in developed countries and consistent with developing countries. ${ }^{18-21}$ The lower and higher prevalence rate of $6.6 \%$ and $52 \%$, respectively has also been reported. ${ }^{22,23}$

The prevalence of EoNS and LoNS was $33.92 \%$ and $3.19 \%$ respectively. EoNS was more common than LoNS in this study. This was compatible with other studies done in developing countries but in contrast, some studies have shown that LoNS was more common. ${ }^{2,20,21}$ In our study it was $11.32 \%$, comparable to other hospital of Nepal. ${ }^{2}$ Birth canal cleansing with antiseptic solution introduced in Malawi and cefoxitin prophylactic antibiotic have substantially lowered the EoNS. ${ }^{24,25}$

Most common morbidities in NICU was neonatal sepsis (186, 62.00\%) followed by neonates born to CRP positive mothers $(64,21.33 \%)$. Out of 86 neonates whose mothers were CRP positive, only 32 (17.20\%) neonates developed sepsis (data not shown). Hence, guideline on NICU admission is necessary to decrease undue admissions in NICU.

Maternal and neonatal factors predict neonatal sepsis. ${ }^{26}$ In this study, neonates born to mothers with maternal fever one or two weeks before delivery, multiparity, and PROM more than 24 hours were more likely to develop neonatal sepsis. Maternal fever and PROM were strong predictors of neonatal sepsis in some studies, ${ }^{27,28}$ while they were not significantly predicting sepsis in other. ${ }^{29}$ Foul smelling liquor, and PV examination $>5$ times have been described as predictors of neonatal sepsis but they were not predicting sepsis in this study. Similarly, delivery via cesarean section, apgar score less than 4 at $1 \mathrm{~min}$ of birth, apgar score less than 7 at $5 \mathrm{~min}$ of birth and preterm deliveries were found to be predictors of neonatal sepsis. This is compatible with some reports where preterm neonates and neonates with low apgar score at 1 minute and 5 minute were likely to develop sepsis. ${ }^{26}$ Low birth neonates are also prone to develop sepsis but this was not a predictor of sepsis in this study. ${ }^{30}$ 
Correct recognition of clinical presentation will help in the early identification and empirical management of sepsis. Among the clinical presentations laid by WHO young infants study group for sepsis, current study identified tachypnoea, grunting, poor feeding, poor cry, cyanosis and vomiting as commonest clinical presentations. These were also common presentations of early neonatal sepsis while fever $\geq 37.5$, irritability and clinical severe jaundice were common for LoNS (data not shown). In other study, the most frequent presentations of suspected cases were respiratory distress, lethargy, jaundice, fever and poor feeding. ${ }^{2}$ Inability to feed, cyanosis, lethargy and convulsion were found to be significantly associated with neonatal sepsis. ${ }^{19}$ Hypothermia, maternal fever, umbilical redness and jaundice were also found to be predictors of sepsis among neonates with late onset sepsis whereas tachypnoea was significant predictor of sepsis in early onset sepsis only. However, in this study hypothermia, pustules (>10), dehydration, diminished movement and bulging fontanels were common presentations of sepsis. These presentations can be a basis in resource limited setting for early identification and treatment of neonatal sepsis.

Out of 51 aetiologies of neonatal sepsis (17.00\%), Gram positives were commonly isolated than Gram negatives which goes along with other report. ${ }^{30}$ In contrast, Gram negatives are also frequently isolated than Gram positives. ${ }^{29}$ CoNS was most common followed by S. aureus. CoNS was also commonly reported pathogen of neonatal sepsis elsewhere. ${ }^{31,32} \mathrm{E}$. coli and $\mathrm{K}$. pneumoniae are commonly encountered in neonatal sepsis but in this study none of the neonates were infected with $\mathrm{E}$. coil while some neonates were infected with K. penumoniae. ${ }^{2,21} \mathrm{~A}$. baumannii and Pseudomonas spp. were also isolated. Majority of Gram positives were resistant to amikacin, cloxacillin, ceftriaxone and meropenem and only few isolates of Gram negatives were resistant to amikacin, ciprofloxacin, and ceftriaxone. Resistance to these antibiotics has already been noted in Nepal and abroad.2,21 Gram positives were more resistant to meropenem than Gram negatives and similar trend was seen elsewhere. ${ }^{21}$

Neonatal sepsis was major cause of mortality in NICU. This was less than mortality rate reported from the study conducted in Patan Hospital (25\%), East Africa (19\%) Pakistan (30-38\%). ${ }^{33-35}$ Significant mortality was due to EoNS (88.66\%). This further highlights the need for early interventions like, antepartum antibiotic prophylaxis, genital cleansing and clean and trauma less deliveries. These interventions will obliterate the transmission of pathogens to newborns at the time of delivery.
Neonatal health has been outlined as an important component of the National Reproductive Health Strategy, Nepal. The National Safe Motherhood Program, which aims to reduce maternal and neonatal mortality, had set the stage for the introduction of a policy for improving neonatal health and survival in the country. Programs like Community Based Integrated Management of Childhood Illness (CB-IMCI), Maternal and Neonatal Tetanus Elimination, (MNTE) Program, Immunization and Nutrition programs, AAMA, Essential Newborn Care and the latest Community based management of Newborn Care program have been successfully ongoing in Nepal. In spite of all these programs, government's efforts and investments in newborn health program, newborns still are dying and the neonatal mortality has stagnated at 33/1000 live births even in $2011 .^{36}$ Neonatal sepsis and infections in newborns need to address to curtail mortality to move towards achieving the MDG 4 in Nepal.

\section{CONCLUSIONS}

Neonatal sepsis was common in this setting and had high mortality. In view of the predictors (cesarian section, apgar score $<4$ at $1 \mathrm{~min}$, and $<7$ at $5 \mathrm{~min}$ ), clinical presentations and organisms of sepsis and their resistance patterns, neneonatal sepsis and related mortality can be significantly reduced by controlling maternal infections, providing clean deliveries, maintaining asepsis during labor, applying stringent criteria for admission in NICU, appropriate antibiotic use, and proper patient safety procedures on infection prevention. There is a need for development of NICU admission guideline, treatment guidelines for sepsis, antibiotic use policy and infection prevention and control guidelines to combat neonatal sepsis. This study has provided a base line data on neonatal sepsis. A population level health policy and systems research to reduce neonatal sepsis through assessment of the feasibility, effectiveness, and cost of promoting clean delivery practices are necessary to curtail neonatal mortality to achieve MDG 4 in Nepal.

\section{ACKNOWLEDGEMENTS}

The authors would like to acknowledge all the study subjects, house officers, interns, residents and staff at $\mathrm{PMWH}$, and UNICEF, Country Office for Nepal for their support thought the study. We would also like to thank UNICEF, Country Office for Nepal for providing funds for this study.

Funding: The fund for this study was provided by UNICEF, Country Office for Nepal. 
Thapa et al. Neonatal Sepsis as a major cause of morbidity in a Tertiary Center in Kathmandu

\section{Conflict of Interests}

There is no conflict of interest to declare. The data and their interpretations in this article are those of the authors and do not necessarily imply to reflect the official opinion of the organizations or institutions involved.

\section{REFERENCES}

1. Stoll BJ, Hansen N. Infections in VLBW infants: Studies from the NICHD Neonatal Research Network. Semin Perinatol. 2003;27:293-301.

2. Jain NK, Jain VM, Maheshwari S. Clinical Profile of Neonatal Sepsis. Kathmandu Univ Med J. 2003;1:117-20.

3. Rosenberg RE, Ahmed AS, Shah SK, et al. Nosocomial Sepsis Risk Score for Preterm Infants in Low-resource Settings. J Trop Pediatr. 2010:56:82-9.

4. Belady PH, Farkouh LJ, Gibbs RS. Intra-amniotic infection and premature rupture of membranes. Clin Perinatol. 1997;24:43-57.

5. Khadka SB, Thapa B, Mahat K. Nosocomial Citrobacter Infection in Neonatal Intensive Care Unit in a Hospital of Nepal. J Nepal Paed Soc. 2011;31:105-9.

6. The WHO Young Infants Study Group. Bacterial etiology of serious infections in young infants in developing countries: results of a multicentre study. Paediatr Infect Dis J. 1999;18:17-22.

7. Bang AT, Bang RA, Bactule SB, Reddy HM, Deshmukh MD. Effect of home based neonatal care and management of sepsis on neonatal mortality: field trial in rural India. Lancet. 1999;354:1955-61.

8. Escobar GJ, Li De-kun, Armstrong MA, et al. Neonatal Sepsis Workups in Infants 2000 Grams at Birth: A Population-Based Study. Pediatrics. 2000;106;256.

9. Gonzalez BE, Mercado CK, Johnson L, Brodsky NL, Bhandari $\mathrm{V}$. Early markers of late-onset sepsis in premature neonates: clinical, hematological and cytokine profile. J Perinat Med. 2003;31:60-68.

10. Kaftan H, Kinney JS. Early onset neonatal bacterial infections. Semin Perinatol. 1998;22:15-24

11. Monica C. District laboratory practices in tropical countries. Part 2. Cambridge University Press. 2005.

12. Manroe BL, Weinberg AG, Rosenfeld CR, Browne R. The neonatal blood count in health and disease. Refernce values for neutrophilic cells. J Pediatr. 1979;95:89-98.

13. Robyn LR, Anton LL, David IT. Early diagnosis of neonatal sepsis using a hematologic scoring system. J Pediatr. 1988;112:761-7.

14. Lawn JE, Cousens S, Darmstadt GL, Paul V, Martines J. Why are 4 million newborn babies dying every year? Lancet. 2004;364:2020

15. Lawn JE, Cousens S, Zupan J. 4 million neonatal deaths: when? Where? Why? Lancet. 2005;365:891-900
16. Ministry of Health and Population, Government of Nepal, New Era, ICF Macro, USAID. Nepal Demographic and Health Survey 2006: New Era 2006.

17. Khinch YR, Kumar A, Yadav S. Profile of Neonatal sepsis. J Coll Med Sci Nepal. 2010;6:1-6.

18. Iregbu KC, Elegba OY, Babaniyi IB. Bacteriological profile of neonatal septicemia in a tertiary Hospital in Nigeria. Afr Health Sci. 2006;6:151-4.

19. Mugalu J, Nakakeeto MK, Kiguli S, Kaddu-Mullindwa DH. Aetiology, risk factors and immediate outcome of bacteriologically confirmed neonatal septicaemia in Mulago hospital, Uganda. Afr Health Sci. 2006;6:120-26.

20. Khalid M AlFaleh. Incidence of late onset neonatal sepsis in very low birth weight infant in a tertiary hospital. SQU Med. 2010;10:227-30.

21. Kayange N, Kamugisha E, Mwizamholya DL, Jeremiah S, Mshana SE. Predictors of positive blood culture and deaths among neonates with suspected neonatal sepsis in a tertiary hospital, Mwanza- Tanzania. RBMC Pediatrics. 2010;10:39.

22. Movahedian AH, Moniri R, Mosayebi Z. Bacterial culture of Neonatal sepsis. Iranian J Publ Health. 2006;35:84-9.

23. Freeman JV, Christian P, Khatry SK, et al. Evaluation of neonatal verbal autopsy using physician review versus algorithm-based cause-of-death assignment in rural Nepal. Paediatr Perinat Epidemiol. 2005;19:323-31.

24. Taha TE, Biggar RJ, Broadhead RL, et al. Effect of cleansing the birth canal with antiseptic solution on maternal and newborn morbidity and mortality in Malawi: clinical trial. BMJ. 1997;315:216-20.

25. Sebitloane H, Moodley J, Esterhuizen TM. Prophylactic antibiotics for the prevention of postpartum infectious morbidity in women infected with human immunodeficiency virus: a randomized controlled trial. Am J Obstet Gynecol. 2008;189:1-6.

26. Soman M, Green B, Daling J. Risk factors for early onset sepsis. Am J Epidemiol. 1985;121:712-19.

27. Bomela $\mathrm{HN}$, Ballot $\mathrm{DE}$, Cooper PA. Is prophylaxis of early onset group B streptococcal disease appropriate for South Africa? S Afr Med J. 2001;91:858-60.

28. Hamida B, Nouaili E, Harouni M, Chaouachi S, Sfar R, Marrakchi Z. Early onset neonatal bacterial infections: a retrospective series of 144 cases. Tunis Med. 2008;86:136-9.

29. Gupta N, Crockett DC, Anthony M, Webster DP. Late onset blood stream infections in a tertiary neonatal intensive care unit. Arch Dis Child Fetal Neonatal Ed. 2011;96:234-7.

30. Samanta S, Farrer K, Breathnach A, Heath PT. Risk factors 
for late onset gram-negative infections: a case-control study. Arch Dis Child Fetal Neonatal Ed. 2011;96:15-8.

31. Vergnano S, Menson E, Kennea N, et al. Neonatal infections in England: the NeonIN surveillance network. Arch Dis Child Fetal Neonatal Ed. 2011;96:9-14.

32. Venkatesh MP, Placencia F, Weisman LE. Coagulase-Negative Staphylococcal Infections in the Neonate and Child. An Update Pediatr Infect Dis. 2006;17:120-27.

33. Shrestha S, Adhikari N. Causes of Neonatal Deaths at Patan
Hospital. J National Health Res Counc. 2002;1:27-30.

34. Jamal M, Khan N. Neonatal Morbidity and Mortality in high risk pregnancies. Med Forum Monthly. 2002;12:9-13.

35. World Health Organization, Child Health and Development: Health of the Newborn, Geneva: World Health Organization 1991.

36. Ministry of Health and Population, Government of Nepal. Nepal Demographic and Health Survey 2011. 